\title{
Study on the Allowable Exposure Time of Temporary Goaf in the Open Stope and Backfill Mining Method with Large Structure Parameters
}

\author{
Xiaosheng Liu $\mathbb{D}^{1,2}$ Weijun Wang, ${ }^{1}$ Yizhong Luo, ${ }^{3}$ and Jin Zhan $^{2}$ \\ ${ }^{1}$ School of Resources, Environment and Safety Engineering, Hunan University of Science and Technology, Xiangtan 411201, China \\ ${ }^{2}$ Changsha Institute of Mining Research Co., Ltd., Changsha 410012, China \\ ${ }^{3}$ School of Resources and Safety Engineering, Central South University, Changsha 410012, China
}

Correspondence should be addressed to Xiaosheng Liu; 13681996@qq.com

Received 21 June 2020; Accepted 21 August 2020; Published 7 September 2020

Academic Editor: Hailing Kong

Copyright (C) 2020 Xiaosheng Liu et al. This is an open access article distributed under the Creative Commons Attribution License, which permits unrestricted use, distribution, and reproduction in any medium, provided the original work is properly cited.

Based on the uniaxial rheological experiment data of iron ore rock mass and filling body in large-scale stope obtained by using the rock servo controlling creep equipment, the characteristics of the creep curve were analyzed. The creep models of iron ore and filling body which can show the attenuation creep of rock were constructed. And a nonlinear creep model was obtained. According to the rheological data of the iron ore and the filling body, the parameters of the new nonlinear creep model were identified to obtain the material parameters of the creep model. Then, the creep model parameters were fitted and reduced to calculate the reasonable exposure time of temporary goaf in the large-scale stope. The results show that the reasonable exposure time of stope is $520 \sim 650$ days, and the reasonable exposure time of filling body is $410 \sim 520$ days. The model can well describe the initial attenuation creep stage and steady creep stage in the creep curve, which proves the correctness and rationality of the model. The study provides a reference for mining design and safety production of similar mines with large-scale stope structure.

\section{Introduction}

In rock engineering, a large number of instability phenomena are related to the creep characteristics of rock. Rock creep is one of the important reasons for the deformation and instability of surrounding rock in rock engineering [1-3]. The rheological property of rock means that the rock presents deformation, fluidity, failure, and other properties with time under the conditions of external load and temperature, mainly presenting the properties of creep, stress relaxation, elastic aftereffect, strain rate effect, aging strength, rheological damage, and fracture [4-6]. In the past few decades, many scholars have carried out experiments on rock creep characteristics and obtained the conclusion that the rock creep continuously adjusts and recombines with time, resulting in rock stress and strain which also continuously increase and change with time [7-11].
In the process of ductile creep, the microcrack growth with time is also one of the main reasons for the failure of hard rock. In the process of brittle and ductile creep, rock samples show different time-dependent crack growth patterns in the microcosmic mechanism, leading to significant differences in macroscopic deformation behavior $[12,13]$. A series of uniaxial compressive strength tests and multistage creep tests are carried out on rock specimens under different immersion conditions. The results show that the peak strength and elasticity modulus of red sandstone not only decrease with water content but also decrease with immersion time, which can be better expressed by the negative exponential function. On the basis of studying the stressstrain curve of rock, many creep models of rock have been put forward by combining with various simple creep elements, such as Maxwell model, Bingham model, Burgers model, generalized Kelvin model, and K-B model. But these models cannot describe the whole process of rock creep very 
well, especially for the accelerated creep stage. Among these models, the K-B model and Burgers model are widely used and are improved to obtain good research results [13-18]. It should be pointed out that, because of the test instrument, the rock creep models under high temperature, high pressure, and anisotropy are seldom discussed, which is also the difficulty of rock creep research in the future.

In recent years, a large number of studies have been carried out on the cemented filling body strength, filling material proportion, backfill mechanical properties, and stability analysis; for example, the factors affecting the strength of tailings filling body are studied through different proportion tests [19], the damage model of tailings filling body is established through tests [20], and the mechanical properties in the roof of tailings cemented filling body are studied [21, 22]. However, there are few papers on the creep research for the cemented filling body in large-scale stope mined by the backfill mining method. Therefore, the establishing creep model of filling body to determine the reasonable exposure time of goaf is not only of theoretical value but also of great necessity to calculate and analyze the stability of filling body in engineering practice. In the whole creep process of rocks and filling body, accelerated creep is relatively difficult to simulate. The current theoretical research focuses mainly on simulating accelerated creep characteristics. In this study, through a series of uniaxial compression creep tests, an ideal nonlinear material element which can simulate accelerated creep characteristics is constructed and then combined with basic elements to simulate the whole creep process. The uniaxial creep tests are carried out on the iron ore rock and filling body under the loading conditions to study the deformation characteristics of rock and filling body under different stress states. On the basis of summarizing the damage research results of different materials, statistical damage is introduced into the composite element model, and the corresponding creep model is established. And the corresponding creep parameters are obtained by model parameter identification. Then, the creep equation is used to predict the timeliness of large-scale stope structure, and the reasonable stope exposure time is discussed from the safety.

\section{Mining Conditions and Requirements of a Large Iron Mine}

An iron mine in Anhui Province, China, is located about $18 \mathrm{~km}$ in the south of Huaihe River. The mining area is basically flat. The surface of the mining area is basically farmland and is part of the residential buildings. In order to safeguard the surface from collapse, strict protection is needed. The deposit is covered by Quaternary topsoil and strongly weathered rock stratum; its average thickness is $120 \mathrm{~m}$, and the thickness of upper clay stratum is tens of meters. The integrity and stability of strongly weathered rock are poor. The occurrence of the ore body is steep, the local structural fracture zone is developed, and the rock and ore are stable. The buried depth of the main ore body is less than $150 \sim 900 \mathrm{~m}$. The ore body trend is nearly north-south and inclines to west, with a dip angle of $68^{\circ} \sim 88^{\circ}$. The thickness of the ore body is $25.5 \sim 96.5 \mathrm{~m}$, the average thickness is $49.65 \mathrm{~m}$, the strike length is about $2000 \mathrm{~m}$, and the average geological grade is $30.69 \%$.

The required production scale of the mine is 7.5 million $\mathrm{t} / \mathrm{a}$, the mining capacity of the stope is $2000 \mathrm{t} / \mathrm{d}$, the ore dilution rate is less than or equal to $10 \%$, and the ore recovery rate is more than or equal to $90 \%$. In order to protect the earth's surface and the structures and to achieve the above technical and economic indicators, it is necessary to adopt the open-stope and backfill mining method with large structure parameter. According to research, the method is divided into three parts: drilling in sublevel, ore drawing in level, and filling in level. The space is open during mining. After mining, the ground pressure is controlled and managed by the filling body and surrounding rock. The stope is vertical to the ore body trend, with a width of $40 \mathrm{~m}$, a length of about $40-80 \mathrm{~m}$, and a height of $100 \mathrm{~m}$. The stope is divided into a room and pillar for mining. The widths of the room and pillar both are $20 \mathrm{~m}$. There is no pillar between the stope and the stope. The sublevel height is $25 \mathrm{~m}$, and the whole stope is divided into 4 sublevels to drill the upward fanshaped medium-deep holes. The mining method is shown in Figure 1.

Because the room and pillar are open during mining, the key to successfully realize the mining method is to ensure that the stope does not collapse and large-scale displacement before filling. The demonstration work is carried out through the creep principle and test.

\section{Creep Experiment}

There are many methods for rock creep experiment, and the most common ones are uniaxial compression experiment, triaxial compression experiment, and shear creep experiment. In order to determine the creep parameters of iron ore and filling body in the underground stope of an iron mine in a short period of time through the test, so as to study the time effect of rock stability, uniaxial compression creep experiment is chosen for the study.

\subsection{Experiment Object and Uniaxial Compression Experiment.} The iron ore belongs to quartz specularite. The filling body has three kinds of cement-sand ratio of $1: 4,1: 6$, and $1: 8$. Due to the long time of creep experiment, this study chooses the quartz specularite and the filling body with cement-sand ratio of $1: 6$ as the experiment objects.

Firstly, the conventional uniaxial compression experiment is carried out on the specimens, and the experiment results are shown in Table 1 . Figure 2 shows the photos of creep experiment specimens.

3.2. Creep Experiment Instrument and Loading Mode. The strengths of the two kinds of specimens in this creep experiment are quite different. The uniaxial compressive strength of iron ore is relatively high, with an average value of $163.59 \mathrm{MPa}$, while that of the filling body is extremely low, and the average uniaxial compressive strength of the filling body with a cement-sand ratio of $1: 6$ is $3.34 \mathrm{MPa}$ in $28 \mathrm{~d}$. So 


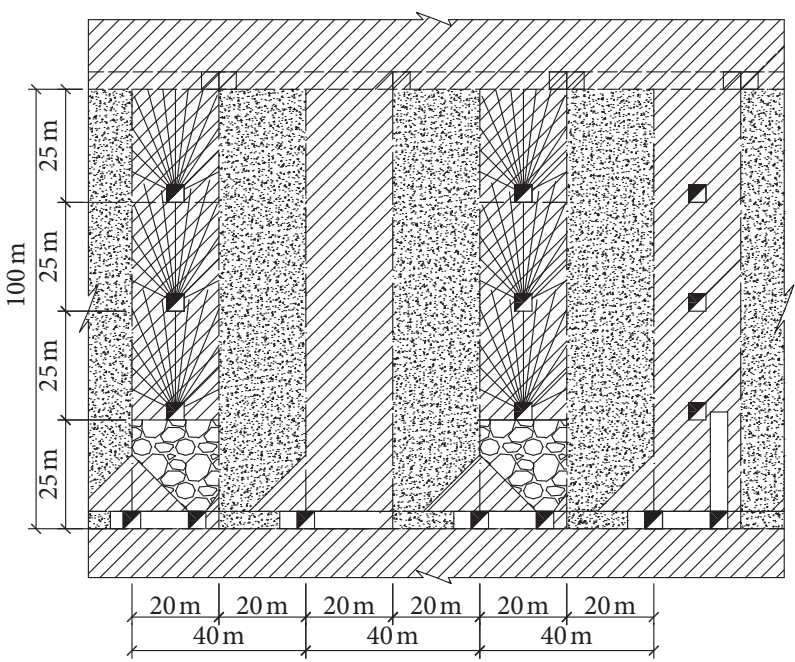

FIgURE 1: The open-stope and backfill mining method.

TABLE 1: Conventional experiment results of the specimens.

\begin{tabular}{lccc}
\hline Specimens & Instantaneous uniaxial compression strength, $R(\mathrm{MPa})$ & Axial ultimate strain, $\varepsilon(\%)$ & Remarks \\
\hline Iron ore & 163.59 & 0.52 & Quartz specularite \\
Filling body & 3.34 & 0.58 & Cement-sand ratio of $1: 6$ \\
\hline
\end{tabular}

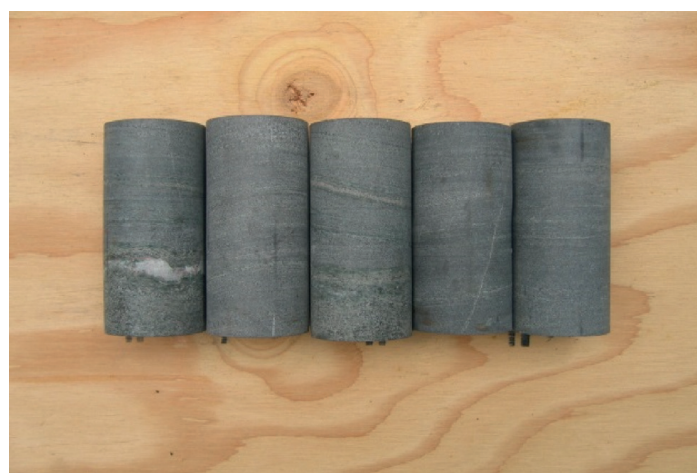

(a)

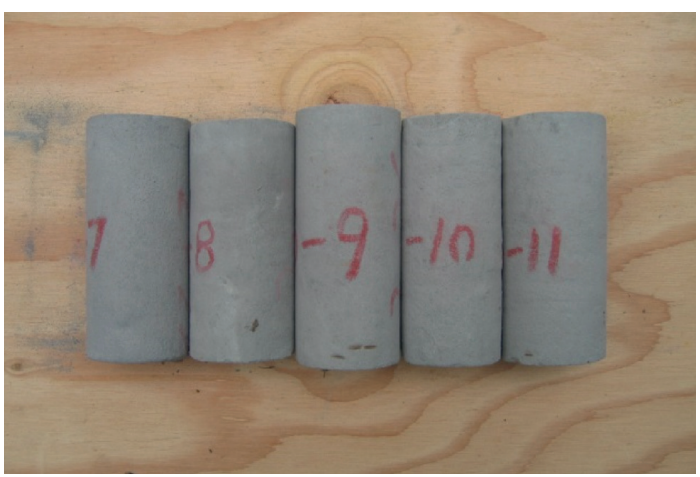

(b)

FIGURE 2: Specimens of creep experiment. (a) Iron ore specimens. (b) Filling body specimens.

it is difficult to complete the test work on the same instrument for two kinds of specimens with great strength difference. Therefore, high requirements are put forward for the experiment instrument, and it is necessary to use different tonnage testing machine for testing.

For the iron ore with high uniaxial compressive strength, an Instron 1346 servo rigid material testing machine is used for testing. For the filling samples with very low uniaxial compressive strength, the Instron 1342 servo rigid material testing machine is used for testing, with the maximum axial pressure of $250 \mathrm{kN}$ and the sensor of $10 \mathrm{kN}$, and its accuracy can meet the observation value of $0.001 \mathrm{~mm}$. The load control mode is adopted in the test, the test data are recorded automatically, and the test curve is drawn synchronously.

The loading mode is the constant loading mode. A group of specimens with the same rock are used to bear different constant loads. Because of the different properties of the rock specimens, the test results are discrete. However, the test results are reliable and not affected by the loading state. Therefore, the uniaxial creep experiment adopts constant load mode.

\section{Creep Experiment and the Model of Ore and Rock}

The uniaxial creep experiment of iron ore is carried out by using the Instron 1346 servo rigid material testing machine. Before loading, the specimens are placed indoor for $20 \sim 30$ days in the natural environment. The temperature of the experiment environment shall be controlled at $20^{\circ} \mathrm{C} \pm 2^{\circ} \mathrm{C}$. The constant load mode is adopted. Due to the high strength of iron ore, the loading rate is $90 \mathrm{kN} / \mathrm{min}$, which is about 


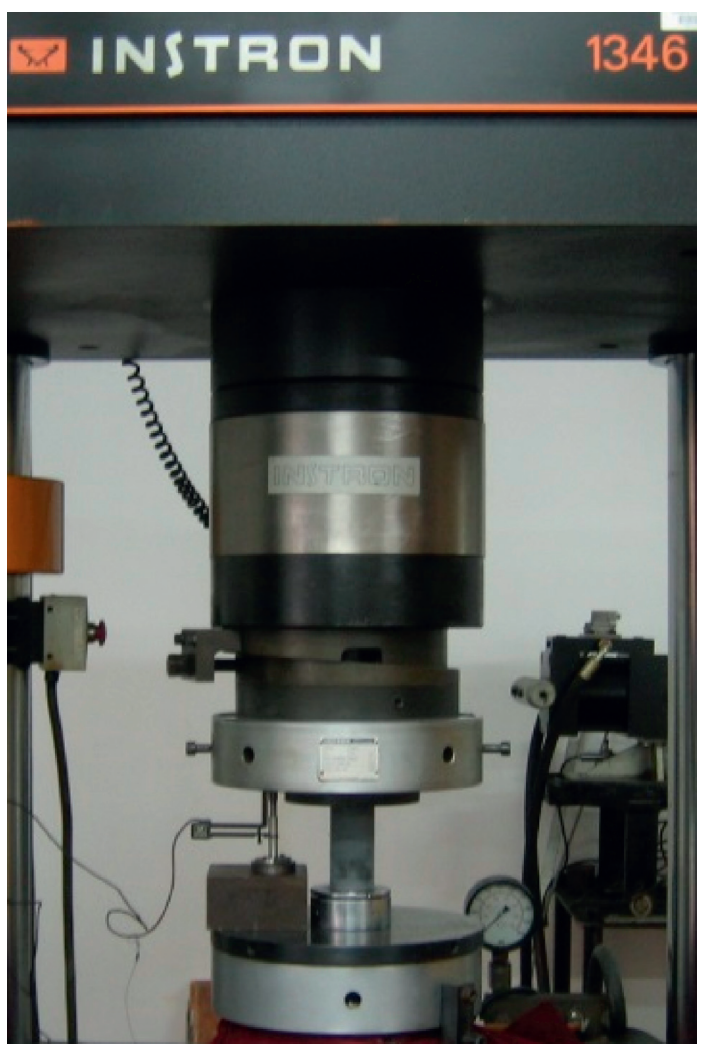

Figure 3: Creep experiment of the iron ore.

$0.75 \mathrm{MPa} / \mathrm{s}$. The axial displacement is recorded by using a displacement extensometer with a gauge distance of $5 \mathrm{~mm}$. The control mode is load control. The creep experiment of iron ore is shown in Figure 3.

After loading the predetermined constant load, the strain is read immediately as the initial strain value of the load. The strain values are recorded at the intervals of $5,10,15$, and $30 \mathrm{~min}$ in the first $1 \mathrm{~h}$ and then are recorded at intervals of half an hour.

Under the action of constant load $(81.80 \mathrm{MPa})$ with a stress level of $50 \% R$, specimen $Y 2-6$ does not damage in 192 hours. Specimen Y2-7 also is not damaged in 192 hours under the action of constant load $(98.15 \mathrm{MPa})$ with the stress level of $50 \% R$. Under the action of constant load $(114.51 \mathrm{MPa})$ of a stress level of $70 \% R$, specimen $Y 2-8$ is not damaged in 192 hours but presents a sign of possible damage. Under the action of constant load (130.87 MPa) with a stress level of $80 \% R$, specimen $Y 2-9$ gets damaged in 175 hours. The creep of each test specimen is shown in Table 2. The test curve of the relationship between axial strain and time of each test specimen is shown in Figure 4.

The iron ore belongs to hard rock, its creep is relatively small at low stress level, and its deformation tends to be stable after a short period of initial creep. But at high stress level, the creep is relatively obvious, which is also proved by this experiment. In the experiment, due to a good control on the load, the accelerated creep process is observed in two specimens besides the attenuation creep process and steady creep process.

The five element model used in rock mechanics is called the B-K model, also known as the Bingham-Vogt model, which is composed of a Bingham body and a Kelvin (Vogt) body in series.

When $\sigma<\sigma_{s}$, the friction plate is a rigid body. This model has the same characteristics as the generalized Kelvin model. The constitutive equation and creep equation of the model are as follows:

$$
\begin{aligned}
\frac{\eta_{k}}{E_{B}+E_{K}} \dot{\sigma}+\sigma & =\frac{E_{B} \eta_{k}}{E_{B}+E_{K}} \dot{\varepsilon}+\frac{E_{B} \eta_{k}}{E_{B}+E_{K}} \varepsilon \\
\varepsilon & =\left(\frac{1}{E_{B}}+\frac{1}{E_{K}}\right) \sigma_{c}-\frac{1}{E_{K}} \sigma_{c} e^{-\left(E_{K} / \eta_{K}\right) t} .
\end{aligned}
$$

When $\sigma<\sigma_{\mathrm{s}}$, the creep of the B-K model is in a stable creep. According to formula (2), when $t=0$, only the Bingham body works, and when $t \longrightarrow \infty$, the damper cylinder does not work, which is equivalent to connecting the spring of the Bingham body and Kelvin (Vogt) body in series.

When $\sigma \geq \sigma_{\mathrm{s}}$, the performance of the B-K model is similar to that of the Burgers model, but the difference is that the stress overcoming the friction resistance $\sigma_{\mathrm{s}}$ in the model should be removed in the B-K model. Therefore, by directly substituting $\left(\sigma-\sigma_{s}\right)$ for $\sigma$ in the constitutive equation of the Burgers model, the constitutive equation of the $\mathrm{B}-\mathrm{K}$ model is obtained as follows:

$$
\ddot{\sigma}+\left(\frac{E_{B}}{\eta_{K}}+\frac{E_{B}}{\eta_{B}}+\frac{E_{K}}{\eta_{K}}\right) \dot{\sigma}+\frac{E_{K} E_{B}}{\eta_{K} \eta_{B}}\left(\sigma-\sigma_{s}\right)=E_{B} \ddot{\varepsilon}+\frac{E_{K} E_{B}}{\eta_{K}} \dot{\varepsilon} .
$$


TABLE 2: Uniaxial creep statistics of the iron ore specimens.

\begin{tabular}{lccccccc}
\hline Specimens & $\begin{array}{c}\text { Stress level } \\
(\% R)\end{array}$ & $\begin{array}{c}\text { Creep stress } \\
(\mathrm{MPa})\end{array}$ & $\begin{array}{c}\text { Predetermined load } \\
(\mathrm{kN})\end{array}$ & $\begin{array}{c}\text { Initial strain } \\
(\%)\end{array}$ & $\begin{array}{c}\text { Final strain } \\
(\%)\end{array}$ & $\begin{array}{c}\text { Creep strain } \\
(\%)\end{array}$ & $\begin{array}{c}\text { Creep time } \\
(\mathrm{h})\end{array}$ \\
\hline$Y 2-6$ & 50 & 81.80 & 153.88 & 0.23 & 0.247 & 0.017 & 192 \\
$Y 2-7$ & 60 & 98.15 & 184.93 & 0.27 & 0.291 & 0.021 \\
$Y 2-8$ & 70 & 114.51 & 216.82 & 0.32 & 0.348 & 0.028 \\
$Y 2-9$ & 80 & 130.87 & 247.59 & 0.36 & 0.483 & 0.123 \\
\hline
\end{tabular}

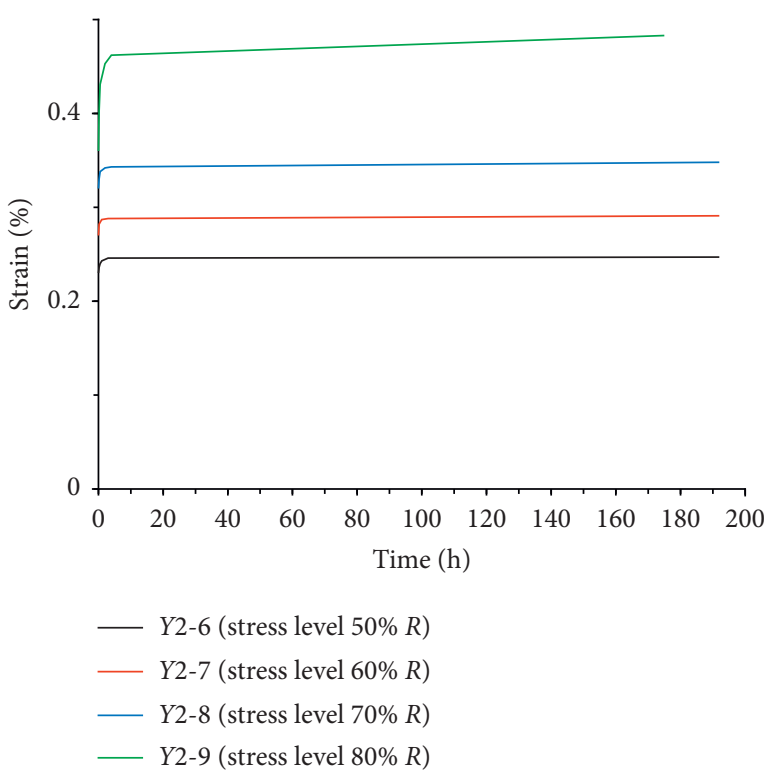

Figure 4: Creep curve of the iron ore specimens.

The creep and unloading equations of the B-K model can be obtained from the creep and unloading equations of the Kelvin body and Bingham body:

$$
\begin{aligned}
& \varepsilon=\frac{\sigma_{c}-\sigma_{s}}{\eta_{B}} t+\frac{\sigma_{c}}{E_{B}}+\frac{\sigma_{c}}{E_{K}}\left(1-e^{-\left(E_{K} / \eta_{K}\right) t}\right) \\
& \varepsilon=\frac{t_{u}}{\eta_{B}}\left(\sigma_{c}-\sigma_{s}\right)+\frac{\sigma_{c}}{E}\left(1-e^{-\left(E_{K} / \eta_{K}\right) t_{u}}\right) e^{-}\left(E_{K} / \eta_{K}\right)\left(t_{u}-t\right)
\end{aligned}
$$

The relaxation equation of the $\mathrm{B}-\mathrm{K}$ model is too complex to be listed here. From equation (4), when $t=0$, only the spring works, and $\varepsilon_{0}=\sigma_{c} / E_{B}$. When $t \longrightarrow \infty, \varepsilon_{\infty} \longrightarrow \infty$, but the change rate tends to be constant, and the creep belongs to metastable creep. Similarly, the unloading equation of the $\mathrm{B}-\mathrm{K}$ model can be obtained by the unloading equation superposition of the Maxwell body and Kelvin body. When $t \longrightarrow \infty, \varepsilon \longrightarrow\left(t_{u} / \eta_{M}\right) \sigma_{c}$, and some permanent deformation remains after unloading.

\section{Creep Experiment and the Model of Filling Body}

The uniaxial creep experiment of filling body is carried out by using the Instron 1342 servo rigid material testing machine. Before loading, the specimens are placed in the indoor for $20 \sim 30$ days in the natural environment. The temperature of the experiment environment shall be controlled at $20^{\circ} \mathrm{C} \pm 2^{\circ} \mathrm{C}$. The constant load mode is adopted, and the loading rate is $2 \mathrm{kN} / \mathrm{min}$, which is about $0.015 \mathrm{MPa} / \mathrm{s}$. The axial displacement is recorded by using an LVDT displacement sensor. The control mode is load control. The creep experiment of filling body is shown in Figure 5.

After loading the predetermined constant load, the axial displacement is read immediately as the initial displacement value of the load. In the first $1 \mathrm{~h}$, the axial displacement values are recorded at the intervals of 5, 10, 15, and $30 \mathrm{~min}$ and then are recorded every half an hour.

Under the action of constant load $(1.00 \mathrm{MPa})$ with a stress level of $30 \% R$, specimen Yc6-7 is not damaged in 200 hours. Specimen Yc6-8 also is not damaged in 200 hours under the action of constant load $(1.34 \mathrm{MPa})$ with a stress level of $40 \% R$. Under the action of constant load (1.67 MPa) with the stress level of $50 \% R$, specimen Yc6-9 is not damaged in 200 hours but presents a sign of possible damage. Under the action of constant load (2.00 MPa) with a stress level of $60 \% R$, specimen Yc6-10 gets damaged in 196 hours. The creep of each test specimen is shown in Table 3. The test curve of the relationship between axial strain and time of each specimen is shown in Figure 6.

The strength of filling body is low, and its creep deformation is large. When the stress level is more than $50 \% R$, the creep is obvious, which experiences three stages: attenuation creep, steady creep, and accelerated creep. There are obvious signs before the material fracture. In the creep curve, there is an upwarping section in rapid increase of change rate.

The Burgers model can well describe the creep curve with initial creep and steady creep, and the model is simple and practical, which has been widely used. Therefore, the Burgers model is selected to describe the compression creep characteristics of the filling body.

The Burgers model is also called the M-K model, which is composed of a Maxwell body ( $\mathrm{M}$ body) and a Kelvin body ( $\mathrm{K}$ body) in series.

The constitutive equation and creep equation of the Burgers model are as follows:

$$
\begin{aligned}
\ddot{\sigma}+\left(\frac{E_{B}}{\eta_{K}}+\frac{E_{B}}{\eta_{B}}+\frac{E_{K}}{\eta_{K}}\right) \dot{\sigma}+\frac{E_{K} E_{B}}{\eta_{K} \eta_{B}} \sigma=E_{B} \ddot{\varepsilon}+\frac{E_{K} E_{B}}{\eta_{K}} \dot{\varepsilon} \\
\varepsilon=\frac{\sigma_{c}}{E_{B}}+\frac{\sigma_{c}}{\eta_{B}} t+\frac{\sigma_{c}}{E_{K}}\left(1-e^{-\left(E_{K} / E_{K}\right) t}\right) .
\end{aligned}
$$

According to equation (7), the creep equation of the Burgers model can be obtained by the creep equation superposition of the Maxwell body and Kelvin body. When 


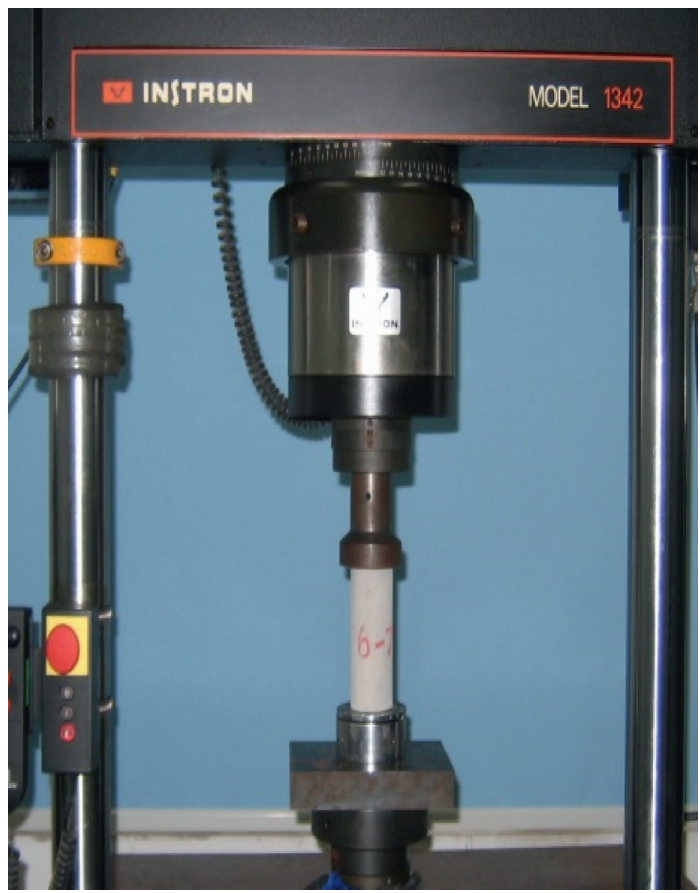

Figure 5: Creep experiment of the filling body.

TABLE 3: Uniaxial creep statistics of the filling body specimens.

\begin{tabular}{lccccccc}
\hline Specimens & $\begin{array}{c}\text { Stress level } \\
(\% R)\end{array}$ & $\begin{array}{c}\text { Creep stress } \\
(\mathrm{MPa})\end{array}$ & $\begin{array}{c}\text { Predetermined load } \\
(\mathrm{kN})\end{array}$ & $\begin{array}{c}\text { Initial strain } \\
(\%)\end{array}$ & $\begin{array}{c}\text { Final strain } \\
(\%)\end{array}$ & $\begin{array}{c}\text { Creep strain } \\
(\%)\end{array}$ & $\begin{array}{c}\text { Creep time } \\
(\mathrm{h})\end{array}$ \\
\hline Yc6-7 & 30 & 1.00 & 2.285 & 0.16 & 0.191 & 0.031 & 200 \\
Yc6-8 & 40 & 1.34 & 0.071 & 0.21 & 0.252 & 0.042 \\
Yc6-9 & 50 & 1.67 & 3.799 & 0.27 & 0.321 & 0.051 \\
Yc6-10 & 60 & 2.00 & 4.530 & 0.35 & 0.545 & 0.195 \\
\hline
\end{tabular}

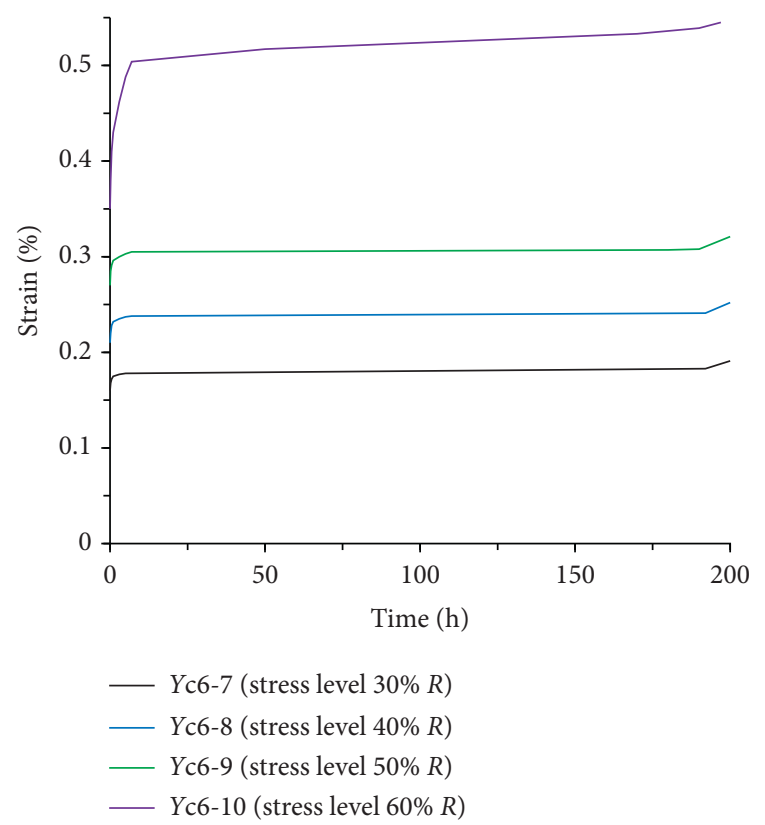

Figure 6: Creep curve of the filling body specimens. $t=0$, only the spring works, and $\varepsilon_{0}=\sigma_{c} / E_{B}$. When $t \longrightarrow \infty$, $\varepsilon_{\infty}$ approaches infinity, but its change rate tends to be constant and the creep belongs to metastable creep.

\section{Creep Model Parameters and Exposure Time Calculation}

The creep constitutive equations of iron ore and backfill in the following sections under uniaxial compression belong to a nonlinear function. In order to determine the parameters of the constitutive equations, the Marquardt method in the least squares method is used to fit the parameters of the creep model.

6.1. Fitting Value of Creep Parameters of Iron Ore. The creep constitutive model of iron ore uses the K-B model for fitting. In the K-B model, there are 5 rheological parameters need to be calculated, in which EB is the elastic modulus. When $\sigma$ acts on the specimen, the elastic deformation caused by EB is completed in an instant. Therefore, when $t=0$, the corresponding ratio of $\sigma$ to $\varepsilon$ is equal to the $\mathrm{EB}$ value. The initial 
TABLE 4: Calculation values of creep parameters of the iron ore.

\begin{tabular}{|c|c|c|c|c|c|c|}
\hline Specimens & Creep stress $\sigma(\mathrm{MPa})$ & $\sum s(\mathrm{MPa})$ & $E_{\mathrm{B}}(\mathrm{GPa})$ & $E_{\mathrm{K}}(\mathrm{GPa})$ & $\eta_{\mathrm{K}}(\mathrm{GPa} . \mathrm{d})$ & $\eta_{\mathrm{B}}$ (GPa.d) \\
\hline$Y 2-6$ & 81.80 & - & 35.57 & 23.32 & 1898.80 & - \\
\hline$Y 2-7$ & 98.15 & - & 36.35 & 34.52 & 3839.21 & - \\
\hline$Y 2-8$ & 114.51 & - & 35.78 & 39.74 & 6766.93 & - \\
\hline$Y 2-9$ & 130.87 & 118.19 & 35.36 & 50.34 & 12765.45 & 6154.82 \\
\hline
\end{tabular}

flow stress can be read directly from the creep curve. The parameters to be determined by the least squares method are $\mathrm{EK}, \eta \mathrm{B}$, and $\eta \mathrm{K}$. The rheological parameters are related to the stress level. It is necessary to fit the creep parameters under different stress levels. During fitting the creep curves of specimens $Y 2-6 \sim Y 2-10$, the correlation coefficients are 0.92 , $0.90,0.93,0.91$, and 0.92 respectively. Table 4 shows the calculation results of creep parameters of iron ore.

6.2. Fitting Value of Creep Parameters of the Filling Body. The creep constitutive model of filling body adopts the Burgers model for fitting. In the Burgers model, there are four rheological parameters need to be calculated, in which $\mathrm{EB}$ is the elastic modulus. When $\sigma$ acts on the specimen, the elastic deformation caused by EB is completed in an instant. Therefore, when $t=0$, the corresponding ratio of $\sigma$ to $\varepsilon$ is equal to the $\mathrm{EB}$ value. Comparing the Burgers model with the K-B model, it is found that the elastic modulus EB of the two models is exactly the same. The other three rheological parameters (EK, $\eta \mathrm{B}$, and $\eta \mathrm{K}$ ) are needed to be determined by the least squares method. The rheological parameters are related to the stress level. Similarly, it is necessary to fit the creep parameters of filling body under different stress levels. The correlation coefficients of the creep curves of specimens Yc6-7 Yc6-11 are 0.95, 0.93, 0.93, 0.92, and 0.94, respectively. Table 5 shows the calculation results of creep parameters of the filling body.

6.3. Recommended Creep Parameters. Because the time of indoor creep experiment is limited, the creep parameters of rock and filling body obtained by tests must have differences with the real creep parameters of rock and backfill on-site. Therefore, the fitting value of creep parameters of iron ore and filling body should be modified. The general method is to make corresponding reduction through reference to similar projects and combining with the engineering geological conditions or viscoelastic displacement inversion results.

Considering the difference between the on-site rock mass and the indoor rock specimens, referring to the research results of similar projects at home and abroad, and combined with the engineering geological conditions of the iron ore and the filling body in the mine, the fitting values of creep parameters in Tables 4 and 5 are reduced. As the joint fissures in iron ore are relatively developed, the reduction coefficient for the iron ore is selected as 0.7. For the filling body, the development degree of the joint fissures is relatively low, and the reduction coefficient is selected as 0.8 . The creep parameters of on-site iron ore body and filling body after modification are shown in Tables 6 and 7, respectively.
6.4. Reasonable Exposure Time of Large-Scale Stope Structure. On the basis of the indoor uniaxial compression creep experiment, the creep models of iron ore (quartz specularite) and filling body with a cement-sand ratio of $1: 6$ are established by analyzing the characteristics of the creep curve. Then, the model parameters are fitted by the least squares method, and the corresponding creep parameters are obtained. Then, the fitting value of creep parameters is modified for the engineering application. So the creep equation can be used to calculate the stability time of iron ore and filling body. This stability time is considered as reasonable exposure time.

The reasonable exposure time for the iron ore and the filling body with the cement-sand ratio of $1: 6$ is from the start of stope blasting to the end of roof-contacted filling. The initial setting time of the filling slurry is about 6-10 hours, and the final setting time is about 2 days. During this time, the filling body gradually develops strength and supports the roof of the stope. Because the solidification time of filling slurry is relatively short, it can be neglected in this study.

The results of the uniaxial compression creep tests are obtained as follows: the ratio of axial ultimate strain to conventional ultimate strain is $93 \% \sim 95 \%$ in the case of creep failure of iron ore and is $94 \% \sim 96 \%$ in the case of creep failure of the filling body.

The creep deformation of iron ore and filling body is related to the stress level. The finite element numerical simulation shows that the stress level of iron ore is generally lower than $100.0 \mathrm{MPa}$, namely, lower than $60 \%$ of the uniaxial compressive strength of iron ore. And the stress level of filling body is generally lower than $2.0 \mathrm{MPa}$, namely, lower than $60 \%$ of the uniaxial compressive strength of filling body.

The axial ultimate strain is 0.49 in the creep failure of iron ore, and the ratio of the axial ultimate strain to the conventional ultimate strain is about $94 \%$. The axial ultimate strain is 0.55 in the creep failure of filling body, and the ratio of the axial ultimate strain to the conventional ultimate strain is $95 \%$. The stress level is $50 \% R \sim 60 \% R$. According to formulas (2) and (7), the stability time of iron ore and filling body is calculated, respectively.

6.4.1. Stability Time of Iron Ore. The equation is established according to the parameters in Table 6 and the relevant initial values. When the stress level is $50 \% R$, the equation is as follows:

$$
0.49=\left(\frac{1}{24.90}+\frac{1}{16.32}\right) \times 81.8-\frac{81.8}{16.32} e^{-(16.32 / 1329.16) t}
$$

When the stress level is $60 \% R$, the equation is as follows: 
TABLE 5: Calculation results of creep parameters of the filling body.

\begin{tabular}{|c|c|c|c|c|c|}
\hline Specimens & Creep stress $\sigma(\mathrm{MPa})$ & $E_{\mathrm{B}}(\mathrm{GPa})$ & $E_{\mathrm{K}}(\mathrm{GPa})$ & $\eta_{\mathrm{K}}(\mathrm{GPa} . \mathrm{d})$ & $\eta_{\mathrm{B}}(\mathrm{GPa} . \mathrm{d})$ \\
\hline Yc6-7 & 1.00 & 0.63 & 1.57 & 0.068 & 29.57 \\
\hline Yc6-8 & 1.34 & 0.64 & 3.06 & 0.14 & 56.83 \\
\hline Yc6-9 & 1.67 & 0.62 & 7.79 & 0.39 & 72.42 \\
\hline$Y c 6-10$ & 2.00 & 0.57 & 11.23 & 0.60 & 89.50 \\
\hline
\end{tabular}

TABLE 6: Recommended creep parameters of iron ore.

\begin{tabular}{|c|c|c|c|c|c|c|}
\hline Specimens & Stress level $(\% R)$ & $\sum s(\mathrm{MPa})$ & $E_{\mathrm{B}}(\mathrm{GPa})$ & $E_{\mathrm{K}}(\mathrm{GPa})$ & $\eta_{\mathrm{K}}(\mathrm{GPa} . \mathrm{d})$ & $\eta_{\mathrm{B}}(\mathrm{GPa} . \mathrm{d})$ \\
\hline$Y 2-6$ & 50 & - & 24.90 & 16.32 & 1329.16 & - \\
\hline$Y 2-7$ & 60 & - & 25.45 & 24.16 & 2687.45 & - \\
\hline$Y 2-8$ & 70 & - & 25.05 & 27.82 & 4736.85 & - \\
\hline$Y 2-9$ & 80 & 82.73 & 24.75 & 35.24 & 8935.82 & 4308.37 \\
\hline
\end{tabular}

TABLE 7: Recommended creep parameters of the filling body.

\begin{tabular}{lccccc}
\hline Specimens & Stress level $(\% R)$ & $E_{\mathrm{B}}(\mathrm{GPa})$ & $E_{\mathrm{K}}(\mathrm{GPa})$ & $\eta_{\mathrm{K}}(\mathrm{GPa} . \mathrm{d})$ & 0.054 \\
\hline Yc6-7 & 30 & 0.50 & 1.26 & 0.11 & 23.66 \\
Yc6-8 & 40 & 0.51 & 2.45 & 0.31 & 45.46 \\
Yc6-9 & 50 & 0.50 & 6.23 & 0.48 & 57.94 \\
Yc6-10 & 60 & 0.46 & 8.98 & $\mathrm{GPa})$ \\
\hline
\end{tabular}

$$
0.49=\left(\frac{1}{25.45}+\frac{1}{24.16}\right) \times 98.15-\frac{98.15}{24.16} e^{-(24.16 / 2687.45) t} .
$$

The stability time of iron ore is calculated as 658.6 days through solving equation (8) and as 527.8 days through solving equation (9). So it is suggested that the reasonable exposure time of iron ore in the stope is $520 \sim 650$ days.

The strength of quartz specularite in this mine is lower than that of magnetite in other mines. If the exposure time is determined based on the quartz specularite in the mining area, the magnetite in other mines will be more stable in the same exposure time.

6.4.2. Stability Time of the Filling Body. The equation is established according to the parameters in Table 7 and the relevant initial values. When the stress level is $50 \% R$, the equation is as follows:

$$
0.55=\frac{1.67}{0.5}+\frac{1.67}{57.94} t+\frac{1.67}{6.23}\left(1-e^{-(6.23 / 0.31) t}\right) .
$$

When the stress level is $60 \% R$, the equation is as follows:

$$
0.55=\frac{2.00}{0.46}+\frac{2.00}{71.60} t+\frac{2.00}{8.98}\left(1-e^{-(8.98 / 0.48) t}\right) .
$$

The stability time of filling body with the cement-sand ratio of $1: 6$ is calculated as 523.2 days through solving equation (10) and as 417.5 days through solving equation (11). So it is suggested that the reasonable exposure time of filling body in the stope is $410 \sim 520$ days.
There are three different cement-sand ratios for the filling slurry, including $1: 4,1: 6$, and $1: 8$. Among them, the filling body with the cement-sand ratio of $1: 6$ is widely used, with a reasonable strength, and its research results provide a good reference for the filling body with other two kinds of cement-sand ratio.

\section{Conclusion}

(1) Uniaxial compression creep tests are carried out on iron ore and filling body, respectively. The creep time of iron ore is 795 hours and that of filling body is 889 hours. The total time of two kinds of samples is 1684 hours.

(2) Through the analysis on the characteristics of creep curves, the creep models of rocks (quartz specularite) and filling body with a cement-sand ratio of $1: 6$ in the large-scale stope are established, respectively. The parameters of the models are fitted by the least squares method to obtain the corresponding creep parameters. Then, the fitting value of creep parameters is modified for the engineering application. According to the stress environment of iron ore and filling body, the creep equations are used to calculate the stability time of iron ore and filling body. The reasonable exposure time of large-scale stope is determined from the aspect of safety.

(3) The stability time of quartz specularite at the stress level of $50 \% R \sim 60 \% R$ ( $R$ is the uniaxial compressive strength) is $527.8 \sim 658.6$ days, so it is 
suggested that the reasonable exposure time of the large-scale stope is $520 \sim 650$ days. The stability time of the filling body with the cement-sand ratio of $1: 6$ at the stress level of $50 \% R \sim 60 \% R$ is $417.5 \sim 523.2$ days, so it is suggested that the reasonable exposure time of the filling body is $410 \sim 520$ days.

\section{Data Availability}

The data used to support the findings of this study are available from the corresponding author upon request.

\section{Conflicts of Interest}

The authors declare that there are no conflicts of interest regarding the publication of this paper.

\section{References}

[1] N. Brantut, M. J. Heap, P. G. Meredith, and P. Baud, "Timedependent cracking and brittle creep in crustal rocks: a review," Journal of Structural Geology, vol. 52, pp. 17-43, 2013.

[2] X. Feng, B. Chen, S. Li et al., "Studies on the evolution process of rockbursts in deep tunnels," Journal of Rock Mechanics and Geotechnical Engineering, vol. 4, no. 4, pp. 289-295, 2012.

[3] X.-T. Feng, S.-F. Pei, Q. Jiang, Y.-Y. Zhou, S.-J. Li, and Z.-B. Yao, "Deep fracturing of the hard rock surrounding a large underground cavern subjected to high geostress: in situ observation and mechanism analysis," Rock Mechanics and Rock Engineering, vol. 50, no. 8, pp. 2155-2175, 2017.

[4] A. Nicolas, J. Fortin, J. B. Regnet et al., "Brittle and semibrittle creep of tavel limestone deformed at room temperature," Journal of Geophysical Research: Solid Earth, vol. 122, no. 6, pp. 4436-4459, 2017.

[5] J. Renner, B. Evans, and G. Siddiqi, "Dislocation creep of calcite," Journal of Geophysical Research: Solid Earth, vol. 107, no. B12, pp. 6-16, 2002.

[6] N. Brantut, P. Baud, M. J. Heap, and P. G. Meredith, "Micromechanics of brittle creep in rocks," Journal of Geophysical Research: Solid Earth, vol. 117, no. B8, 2012.

[7] C. H. Scholz, "Mechanism of creep in brittle rock," Journal of Geophysical Research, vol. 73, no. 10, pp. 3295-3302, 1968.

[8] D. M. Cruden, "A theory of brittle creep in rock under uniaxial compression," Journal of Geophysical Research, vol. 75, no. 17, pp. 3431-3442, 1970.

[9] R. J. Martin, "Time-dependent crack growth in quartz and its application to the creep of rocks," Journal of Geophysical Research, vol. 77, no. 8, pp. 1406-1419, 1972.

[10] B. K. Atkinson, "Subcritical crack propagation in rocks: theory, experimental results and applications," Journal of Structural Geology, vol. 4, no. 1, pp. 41-56, 1982.

[11] N. L. Carter and F. D. Hansen, "Creep of rocksalt," Tectonophysics, vol. 92, no. 4, pp. 275-333, 1983.

[12] J. Zhao, X. T. Feng, X. Zhang, and C. Yang, "Brittle and ductile creep behavior of Jinping marble under true triaxial stress," Engineering Geology, vol. 258, 2019.

[13] C. Yu, S. Tang, C. A. Tang et al., "The effect of water on the creep behavior of red sandstone," Engineering Geology, vol. 253 , pp. 64-74, 2019.

[14] N. Cristescu and U. Hunsche, Time effects in rock mechanics, Vol. 350, Wiley, New York, NY, USA, 1997.

[15] Ö. Aydan, T. Ito, U. Özbay et al., "ISRM suggested methods for determining the creep characteristics of rock," Rock
Mechanics and Rock Engineering, vol. 47, no. 1, pp. 275-290, 2014.

[16] C. F. Yang and Y. J. Zeng, "Investigation on creep damage constitutive theory of salt rock," Chinese Journal of Rock Mechanics and Engineering, vol. 21, no. 11, pp. 1602-1604, 2002.

[17] L. S. Tsai, Y. M. Hsieh, M. C. Weng, T. H. Huang, and F. S. Jeng, "Time-dependent deformation behaviors of weak sandstones," International Journal of Rock Mechanics and Mining Sciences, vol. 45, no. 2, pp. 144-154, 2008.

[18] Z. Tomanovic, "Rheological model of soft rock creep based on the tests on marl," Mechanics of Time-dependent Materials, vol. 10, no. 2, pp. 135-154, 2006.

[19] K. Zhao, X. Yu, and S. T. Zhu, "Acoustic emission investigation of cemented paste backfill prepared with tantalum-niobium tailings," Construction and Building Materials, vol. 237, Article ID 117523, 2020.

[20] K. Zhao, Q. Wang, S. Gu et al., "Mining scheme optimization and stope structural mechanic characteristics for a deep and large ore body," Journal of Minerals, vol. 71, no. 11, pp. 4180-4190, 2019.

[21] K. Zhao, H. B. Yan, and X. Feng, "Stability analysis of pillar based on energy law," Chinese Journal of Theoretical and Applied Mechanics, vol. 48, no. 4, pp. 976-983, 2016.

[22] K. Zhao, Q. Wang, Y. Yan et al., "Geological structural surface evaluation model based on unascertained measure," Geofluids, vol. 2019, pp. 1-7, 2019. 